\title{
Отечественные дискретные компоненты для поверхностного монтажа: насколько верны стереотипы
}

Когда говорится о применении отечественной ЭКБ, часто в первую очередь подразумеваются критические компоненты, такие как микропроцессоры. Они во многом задают функциональные характеристики изделия и занимают существенную долю в структуре его стоимости. Однако сложно представить себе электронное устройство без дискретных компонентов, и выбор этих компонентов, в особенности пассивных, для применения в изделии кажется проще: у них лишь несколько характеристик, и если они их обеспечивают, то вполне могут быть заложены в изделие. Тем не менее, несмотря на наличие российских производителей, применение отечественных дискретных компонентов не столь широко. С ними связан ряд стереотипов, ограничивающих их использование, среди которых высокая цена, длительные сроки поставки, а также - что очень немаловажно в современных условиях неготовность к автоматизированному поверхностному монтажу.

Верны ли эти стереотипы сегодня, или они - уже пережиток прошлого, отвечают ли отечественные дискретные компоненты современным требованиям автоматизации, какие существуют проблемы применения этих изделий и что могло бы помочь их преодолеть - об этом мы попросили высказать свое мнение представителей российских производителей дискретных компонентов, а также контрактных производств - компаний, которые осуществляют сборку печатных узлов для различных заказчиков.

Синим цветом обозначены мнения представителей контрактных производств, красным - производителей компонентов.

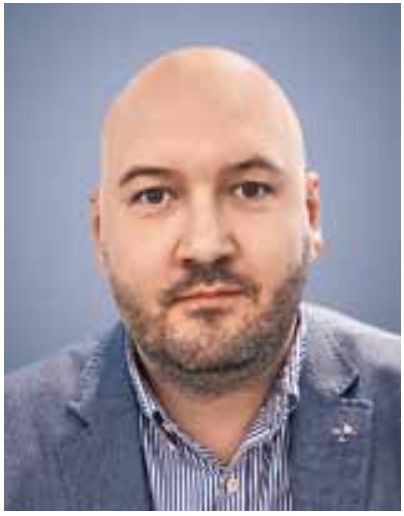

заказчика. А конструкторы редко закладывают в документацию российские пассивные компоненты. По всей видимости, это связано с доступностью информации об ЭКБ и с тем, насколько удобна та форма, в которой она предоставляется. Если на импортные компоненты всегда есть datasheet, эта информация легко находится

На нашем контрактном производстве применяется отечественная пассивная ЭКБ для поверхностного монтажа, но очень редко и практически исключительно совсем простые компоненты: чипрезисторы и, в меньшей степени, керамические конденсаторы.

В основном применение компонентов диктуется документацией

Дмитрий Семёнов, генеральный директор 000 «Макро ЕМС» 
монтажа. С проблемами паяемости в печах оплавления мы тоже не сталкивались.

Если говорить о более сложных отечественных пассивных компонентах, например танталовых конденсаторах, у нас нет сведений о российской продукции такого типа, поставляемой в упаковках, позволяющих выполнять их автоматизированный монтаж. Наши заказчики не закладывают в свои изделия российские компоненты такого типа. Соответственно, мы, как контрактный производитель, их не используем.

Среди основных сложностей применения отечественной ЭКБ я бы отметил вопросы цены и сроков поставки. В наших изделиях не применяются компоненты категории качества ВП, поэтому проблема высокой цены используемой нами российской ЭКБ, на мой взгляд, определяется не обеспечением качества, дополнительными проверками и испытаниями, а элементарно малыми объемами выпуска. В сравнении с китайской продукцией, выпускаемой в массовых количествах, конечно, российские пассивные компоненты оказываются дороже. Но отличие в цене - не в десятки, а в полтора-два раза, и, учитывая то, что эти компоненты сами по себе дешевые, данная проблема - не самая критичная.

Более важный вопрос - сроки поставки, доступность компонентов. На складах импортная ЭКБ присутствует в более широкой номенклатуре, чем отечественная. Более того, можно сказать, что в принципе поставка российских компонентов со склада - редкость. Обычно она поставляется только под заказ с длительными сроками изготовления.

\section{Роман Мартынов, главный инженер АО «Ресурс»}

Резистор - самый распространенный радиоэлемент во всей радиоэлектронной промышленности. Я могу со 100\%-ной уверенностью сказать, что абсолютно на любой плате любого устройства вы найдете хотя бы один резистор.

AO «Ресурс» - высокотехнологичное предприятие, обладающее автоматизированными техпроцессами. Наша продукция включает фольговые, прецизионные, металлопленочные, углеродистые и толстопленочные резисторы, наборы постоянных непроволочных толстопленочных резисторов. Мы производим ЭКБ категорий качества ОС, ВП и изделия с приемкой ОТК.

АО «Ресурс" является самым крупным производителем резисторов для поверхностного монтажа в России и странах CHГ. Наши SMD-резисторы категории качества ВП используются в каждом образце ВВСТ.

Хотя технически наше предприятие готово полностью обеспечить сектор OПK SMD-резисторами отечественного производства, многие предприятия-потребители необоснованно применяют импортные аналоги, потому что данные позиции были заложены в КД при разработке.

Вообще, нежелание потенциальных потребителей ЭКБ менять поставщика, пробовать компоненты нового производителя даже при равных условиях: качестве, цене, сроках поставки и т. п. - одна из основных проблем низких объемов потребления ЭКБ отечественного производства. Необходимы меры, которые предоставляли бы отечественным производителям ЭКБ преимущества по сравнению с импортными аналогами. Страны Восточной и Юго-Восточной Азии научились делать простую массовую ЭКБ по низкой цене, обладающую высоким качеством, которое устраивает большинство потребителей. Поэтому конкурировать на этом рынке практически невозможно. Необходимы центры локализации производств материалов для ЭКБ, производителей ЭКБ и потенциальных потребителей. Даже если применять дешевые импортные материалы, цена использованного материала зачастую превышает стоимость конечного продукта ЭКБ ИП. Как следствие, цена отечественных компонентов оказывается выше импортных аналогов.

В решении этой проблемы могли бы помочь такие меры государственной поддержки, как таможенные пошлины, налоговые каникулы для производителей ЭКБ, содействие локализации, поддержка развития материалов для обеспечения снижения цен и повышения их качества. Кроме того, пользу принес бы уход от программно-целевых методов управления в компонентной отрасли.

Еще одна причина заключается в том, что у отечественных предприятий - производителей ЭКБ, как правило, отсутствуют сертификаты международного образца (ISO 9001, RoHS, 
(Е и т. п.), хотя изделия зачастую соответствуют этим требованиям.

Кроме того, существует стереотип, что в России отсутствует качественная ЭКБ. В частности, это связано с плохой осведомленностью о наличии отечественных производителей компонентов и информированностью об их продукции, отсутствием технических данных в форме datasheet на российскую ЭКБ, а также с тем, что ТУ высылаются предприятиями только при условии покупки компонента. Немаловажную роль играет низкая информативность сайтов предприятий - изготовителей ЭКБ.

Мыготовы опровергнуть стереотип об отсутствии высококачественных отечественных резисторов. На сегодняшний момент наше предприятие осуществило достаточно много пробных поставок продукции для оценки ее качества, по которым получены положительные заключения. В настоящее время осуществляются поставки резисторов для российских производителей электроники в объемах, исчисляемых миллионами штук.

Еще один устойчивый стереотип - более длительные сроки поставки российской ЭКБ в сравнении с зарубежными аналогами. Здесь мы тоже готовы доказать, что в случае нашей продукции это не так: АО «Ресурс» по договору гарантирует срок 30 дней от момента заказа до выпуска готовой продукции; по факту же мы отгружаем продукцию гораздо быстрее. Причем не имеет значения, идет ли речь о часто используемом номинале или, наоборот, очень редком.

Также многие считают, что SMD-компоненты отечественного производства непригодны для автоматизированного монтажа. SMD-резисторы производства АО «Ресурс» полностью соответствуют требованиям, предъявляемым к монтажу на автоматизированных линиях. Они имеют правильную геометрическую форму и минимальный разброс по размерам; снабжены идентификационной маркировкой, начиная с типоразмера 0603 (так же как и резисторы ИП); поставляются в картонной или блистер-ленте на катушке в соответствии с международными требованиями автоматизированного монтажа.

Что касается стоимости в сравнении с зарубежными аналогами, наша продукция категории качества ВП сопоставима по цене с иностранной продукцией категорий military и space, а изделия категории качества ОТК - с аналогичной продукцией мировых лидеров по производству ЭКБ (Vishay, Bourns, Yageo и др.). Соревноваться по цене с китайскими резисторами noname не представляется возможным: это сильно повлияет на качество выпускаемой продукции.

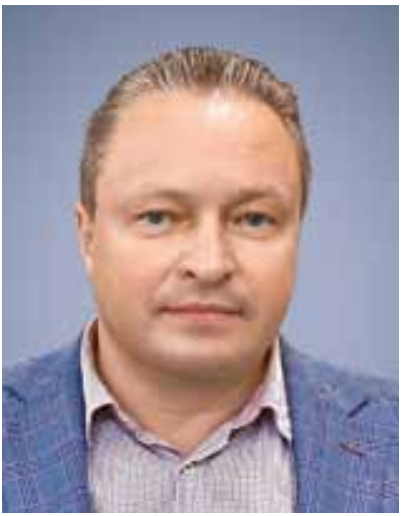

По выводным компонентам отмечу, что в основном из сборочных цехов идут негативные отзывы, связанные с количеством в упаковке. Часто оно никак не нормируется, как будто компоненты в упаковку кладут по весу или "на глаз». Также нарекания связаны с некачественной маркировкой: ее трудно читать, либо она вообще отсутствует.

Срок производства компонентов бывает неоправданно велик. Приходится искать замену, в том числе среди импортнойЭКБ, и договариваться с заказчиком о такой замене, что отнимает массу времени и сил.

Также бедой всей отечественной ЭКБ является высокая цена. Есть приятные исключения, но они пока именно исключения. Для масс-продакшн это не выход.

В отношении применения ЭКБ для поверхностного монтажа, повторю, у нас опыта нет, но мне приходилось сльшать от партнеров и конкурентов, что есть вопросы к геометрии компонентов и к большому разбросу электрических параметров, что для ответственного применения недопустимо.

По всем этим причинам мы стараемся избегать использования отечественной ЭКБ и при любой возможности ищем ей замену.

Необходимо отметить, что начинают проявляться и положительные тенденции. В настоящее время в работе есть проект с использованием отечественной ЭКБ. Мы контактируем с несколькими производствами и обнаружили, что появляются первые 
ласточки, отличающиеся в лучшую сторону от общей массы. Ребята включили даже элементы промышленного дизайна для более привлекательного вида компонента. Называть производителей не буду. Скажу, что речь идет, например, о твердотельном реле.

Ситуация, когда даже пассивные компоненты у нас не получается делать, - не укладывается в голове. Есть предпосылки для изменения, но их гораздо меньше, чем препятствий. И главное препятствие, с моей точки зрения, - мизерное потребление.

Думаю, правительство страны должно было давно озаботиться этим вопросом. Толчком для подъема отечественной промышленности, производящей ЭКБ, могут стать три несложные вещи: заградительные пошлины на импорт; поддержка отечественных производителей - реальная, для всего рынка, а не для двух-трех компаний (например, налоговые каникулы на 3-4 года, беспроцентный заем или ссуда); программа, обязывающая разработчиков электроники закладывать отечественную ЭКБ в новые разработки. Такая программа не должна быть в ущерб качеству конечных изделий. У разработчиков должны быть дополнительные мотивы закладывать в изделия отечественные компоненты, а таких мотивов я пока не вижу.

\section{Дмитрий Прохошин, генеральный директор 000 «Кулон»}

ООО «Кулон» является основоположником отечественного выпуска изделий из керамических материалов и одним из немногих заводов, сохранившихся и развивающихся до сих пор. Изделия производства ООО “Кулон" применяются во всей технике специального назначения: от кабельных сборок до космических спутников. На сегодняшний день основным направлением развития завода является разработка и внедрение новых технологий для гражданского рынка продукции, например разработка конденсаторов из неблагородных металлов с целью импортозамещения. Увеличение занимаемой доли рынка гражданской продукции приведет к ускорению развития технологий и существенному росту объема производства.

Как показывают отзывы потенциальных потребителей, для многих оказывается удивительным, что отечественное производство пассивных компонентов в принципе существует и способно полностью закрывать потребность рынка. существует также миф о том, что российские конденсаторы сильно уступают иностранным по техническим параметрам. Безусловно, отставание присутствует, однако оно легко устранимо при наличии конкретных запросов потребителей. Таким образом, всплывают проблемы недостаточной информационной поддержки, а также отсутствия заградительных мер со стороны государства. При решении указанных вопросов запросы конечных потребителей доходили бы до завода-изготовителя оперативнее, что помогло бы наладить взаимовыгодное сотрудничество, а также задало бы направление развития не только конкретного изготовителя, а всей отрасли. Российские производители, в частности наш завод, стремятся развивать технологии. С этой целью мы проводим полную модернизацию технологических линий для производства нашей продукции.

Существует еще одна проблема, которая замедляет процесс освоения новых технологий: остается высокой цена на сырье для изготовления керамических композиций (например, на мелкодисперсный титанат бария). Все поставщики являются иностранными компаниями. Отечественные поставки основных требуемыхвидов сырья и материалов отсутствуют.

При наличии высоких требований к надежности наших изделий для их использования в аппаратуре с длительным сроком эксплуатации применяется ряд благородных металлов (палладий, серебро и их сплавы), что увеличивает цену изделия, однако стоимость всё равно остается значительно ниже аналогичных изделий иностранного производства. Если говорить о гражданском рынке, то составить конкуренцию иностранным производителям позволит освоение технологического процесса изготовления многослойных монолитных конденсаторов с высокими удельными характеристиками с использованием в качестве электродов неблагородных металлов. Однако основные научные достижения в плане материаловедения в нашей отрасли основаны на патентах 1980-1990-х 
годов. Хотелось бы видеть отечественные лаборатории и НИИ, занимающиеся разработками перспективных материалов для выполнения задач нашего предприятия.

Многих интересует вопрос готовности конденсаторов к автоматизированному монтажу. Еще 10 лет назад на основе современного иностранного опыта была освоена технология изготовления чип-конденсаторов с гальваническими покрытиями контактных поверхностей с подслоем, улучшающим паяемость изделий. Барьерный никелевый подслой предотвращает диффузию серебра в олово, тем самым улучшая паяемость контактных площадок конденсатора, и позволяет использовать групповую пайку паяльными пастами. Данный техпроцесс значительно улучшает качество нанесения покрытия контактных поверхностей.

По своим техническим характеристикам конденсаторы полностью соответствуют действующим техническим условиям, что неоднократно подтверждено результатами испытаний. Такие изделия могут быть успешно упакованы в блистер-ленту для последующего автоматического монтажа у потребителей.

Таким образом, ООО «Кулон» обладает как оборудованием, таки современным технологическим процессом, что позволяет поставлять компоненты, подготовленные для автоматизированного монтажа. Мы будем только рады, если доля заказов на такие изделия увеличится.

ООО «Кулон» всегда готово к любым вариантам сотрудничества. Уже существуют примеры работ с рядом предприятий по удовлетворению запросов на изделия, имеющие расширенную шкалу характеристик относительно стандартных ТУ, а также габаритных размеров компонентов. Мы были бы рады сотрудничеству с потребителями с оказанием взаимовыгодных услуг по созданию специальной оснастки и проведению более широких исследований по определению функциональных зависимостей параметров наших изделий в более широком спектре частот, исследованию микроструктуры и т.д. и готовы к пробным поставкам для российских контрактныхпроизводств для оценки ими нашей продукции.

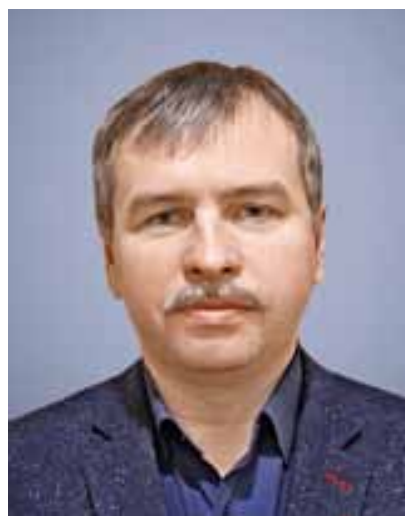

\section{Сергей Фёдоров, директор по производству ООО «АТ»}

Наша компания применяет отечественные электронные компоненты наряду с импортными. Так как мы являемся контрактным производителем электроники, в большинстве случаев то, какая ЭКБ должна применяться, определяется заказчиком. Это касается и выбора между компонентами отечественного и зарубежного производства, и выбора определенного производителя из нескольких зарубежных. В тех случаях, когда у нас есть возможность предложить аналоги компонентам, указанным в спецификации на изделие, выбор в первую очередь осуществляется в пользу зарубежной ЭКБ. Причины банальны: доступность на рынке, сроки поставки, цена, качество, готовность к автоматизированному монтажу.

Вообще говоря, на вопрос, готовы ли отечественные компоненты к автоматизированному монтажу, нельзя ответить однозначно. Если говорить о компонентах, производство которых началось в последние несколько лет, то да, прогресс есть. Это качественные изделия, в этом аспекте ничем не уступающие зарубежным аналогам. Наша компания участвовала в исследованиях по совместимости поверхностно монтируемых резисторов нескольких отечественных производителей с современными технологиями монтажа. Результаты оказались отличными. При этом техническая документация на эти электронные компоненты совершенно не соответствует современным требованиям. Например, в ней отсутствует информация о рекомендациях производителей по профилям пайки для конвекционной и парофазной технологий, современным технологиям отмывки и т. д. С микросхемами ситуация печальнее: они приходят с неотформованными выводами, а значит, и автоматизированный монтаж применять нельзя.

Если же мы говорим об электронных компонентах, производство которых ведется много лет, то, как правило, они не соответствуют современным требованиям монтажа: покрытия выводов предназначены в лучшем случае для пайки волной или требуют применения специализированных припоев, отсутствует упаковка для автоматизированного монтажа, с технической документацией такие же проблемы ит.д. 
Для применения тех или иных компонентов имеют значение как их цена, так и сроки поставки, причем, если говорить о коммерческих заказах, сроки поставки - в первую очередь. На мой взгляд, электронные компоненты всегда должны быть на складе у производителя, либо должен быть минимальным срок их производства в нужном количестве. Они должны быть доступны по цене, сопоставимой с зарубежными аналогами. В этом случае есть надежда на коммерческий успех в конкуренции с зарубежными электронными компонентами, которые еще нужно доставить.

К моему большому сожалению, производители отечественных компонентов не сумели вовремя среагировать на рост производства в приборостроительной отрасли нашей страны. В то время, когда на производствах появлялись новые автоматизированные линии, внедрялись современные технологии, новых отечественных электронных компонентов появлялось крайне мало, а современным требованиям автоматизированного монтажа соответствовало еще меньше.

Тем не менее, в отношении судьбы отечественных электронных компонентов я сохраняю оптимизм. Требования к производству электронных компонентов, предназначенных для автоматизированного монтажа, сформировались уже довольно давно, и отечественным производителям достаточно их учитывать в своей работе. То же касается управленческихи маркетинговых решений. я желаю нашим производителям электронных компонентов как можно быстрее преодолеть образовавшийся разрыв и занять достойное место на рынке электронных компонентов.

\section{Владимир Громов, директор по развитию и новой технике АО «Группа Кремний ЭЛ»}

Применение дискретных компонентов для поверхностного монтажа нашего производства растет в соответствии с тенденцией микроминиатюризации радиоэлектронной аппаратуры. В прошлом году объем таких компонентов в продукции нашего предприятия составлял 15\%, по итогам последних месяцев 2019 года их доля выросла до $50 \%$.

В текущем году на нашем предприятии были внедрены современные материалы и оборудование для производства дискретных компонентов поверхностного монтажа. В настоящее время мы производим SMD-компоненты в следующих корпусах: SOT-23, SOT-89, а также в корпусах с повышенной рассеиваемой мощностью тО-263 (3, 5, 7), ТО-252 (2, 3). Проводятся опытные работы по внедрению корпусов DFN-10, QFP-100. Широко применяются металлокерамические корпуса SMD-0,5 (1, 2). По нашему заказу AO «зПП» (г. Йошкар-Ола) разработаны и освоены новые мощные многовыводные SMD-корпуса MK 5, MK 8, MK 12 .

Пробные поставки российским производителям дискретных SMD-компонентов для оценки характеристик - наша стандартная практика, а перечисленные выше корпуса широко используются в серийном производстве.

При производстве металлополимерных малогабаритных SMD-корпусов мы используем современные материалы: многорядные (8 рядов) медные выводные рамки, герметик - композит марки ELER-8, профилированные медные рамки в корпусах с повышенной мощностью рассеивания. Сборка, герметизация и классификация электронных компонентов в SMD-корпусах производится на современном автоматизированном оборудовании. При герметизации используются многоплунжерные прессформы с повышенной точностью изготовления. Для производства опытных образцов выводных рамок имеется возможность применения лазерного или химического фрезерования.

При использовании многоплунжерных прессформ с повышенной точностью изготовления качество композитных SMD-корпусов находится на уровне лучших зарубежных производителей.

Вышесказанное опровергает стереотипы о низкой надежности отечественных дискретных SMD-компонентов. Продукция нашего предприятия и ее транспортная упаковка применяются при автоматизированном монтаже на платы. В конкуренции по цене с зарубежными производителями мы проигрываем вследствие малых тиражей выпуска. Для снижения цен основным фактором видится увеличение объемов производства.

Maтериал подготовлен Ю. С. Ковалевским 